\title{
Evidence that the B2 chain of laminin is responsible for the neurite outgrowth-promoting activity of astrocyte extracellular matrix
}

\author{
Jerome R. Wujek ${ }^{1}$, Hana Haleem-Smith ${ }^{1}$, Yoshihiko Yamada ${ }^{2}$, Robert Lipsky ${ }^{1, *}$, \\ Yueh Tze Lan ${ }^{3}$ and Ernst Freese ${ }^{1}$ \\ ${ }^{I}$ Laboratory of Molecular Biology, National Institute of Neurological Disorders and Stroke, National Institutes of Health, Bethesda, MD 20892 \\ (U.S.A.), ${ }^{2}$ Laboratory of Developmental Biology and Anomalies, National Institute of Dental Research, National Institutes of Health, \\ Bethesda, MD 20892 (U.S.A.) and ${ }^{3}$ Tufts University School of Medicine, Boston, MA 02111 (U.S.A.)
}

(Accepted 24 April 1990)

Key words: Laminin; Neurite outgrowth; Astrocyte; Extracellular matrix; Neuron; PC12 cell

\begin{abstract}
Extracellular matrix (ECM) derived from cerebral cortical astrocytes stimulates neurite outgrowth from pheochromocytoma (PC12) cells in the absence of the classical nerve growth factor (NGF). We have shown here that astrocyte ECM can also stimulate neurite outgrowth from primary cultures of central nervous system (CNS) neurons. Using PC12 cells for a quantitative assay, we also demonstrated that the neurite growth-promoting activity increased as the astrocytes matured in vitro: ECM from older astrocytes (3-12 weeks in vitro) exhibited two-fold more neurite growth-promoting activity than ECM for younger astrocytes ( 5 days to 2 weeks in vitro). We applied various antibodies to identify the neurite growth-promoting factor of astrocyte ECM and found that anti-laminin inhibited neurite outgrowth by 50\%, whereas anti-fibronectin and anti-NGF had no effect. Immunoblots, using laminin chain-specific antibodies, and cDNA hybridization of laminin mRNA demonstrated that cultured astrocytes synthesize only the B2 chain of laminin. This suggests that the B2 chain of laminin suffices to stimulate neurite outgrowth.
\end{abstract}

\section{INTRODUCTION}

A fundamental characteristic of the developing nervous system is the orderly growth of axons along specific pathways to reach their proper targets. Studies of the embryonic central nervous system (CNS) in mammals and amphibians have indicated that radial glial cells act as substrates to promote and guide axonal growth ${ }^{52,55}$. In the developing CNS of fishes and amphibians, neuroepithelial cells form extracellular channels ${ }^{27,52,54,55}$. These channels are filled with extracellular matrix (ECM; a meshwork of glycoproteins and other macromolecules closely surrounding the cell). As development continues, axons invade and grow within these ECM-filled channels, suggesting that the ECM may be responsible for stimulating and guiding the growth of embryonic axons.

In vitro systems have been used to further investigate the cellular and molecular interactions between glial cells and growing axons. Noble et al. ${ }^{40}$ and Fallon ${ }^{20}$ demonstrated that rat CNS neurons exhibited greater neurite outgrowth on cultured astrocytes than on non-glial cells. Since this effect could not be duplicated by conditioned culture medium, the authors concluded that cell surface interactions were responsible for the stimulation of neurite outgrowth. Another study has shown that the isolated astrocyte ECM of rats can promote neurite outgrowth from PC12 cells ${ }^{67}$. Neurite outgrowth from chick ciliary ganglion cells was partially inhibited on glial cell surfaces by antibodies against laminin receptors, laminin being a component of the ECM, and by antibodies against $\mathrm{N}$-cadherin, a $\mathrm{Ca}^{2+}$-dependent cell adhesion molecule in the cell membrane ${ }^{62,63}$. A combination of both antibodies produced near complete inhibition of neurite outgrowth ${ }^{62}$. In addition, culture conditions that eliminated the majority of ECM molecules from the astrocyte cell surface did not appreciably diminish neurite outgrowth from dorsal root ganglion cells seeded on these astrocytes ${ }^{1}$. These results indicate that some neurite outgrowth-promoting activity resides in both the ECM and the cell membrane. In our studies, we have focused on the effects of astrocyte ECM on neurite outgrowth from CNS neurons. We report that primary cerebellar granule neurons and cerebral cortex explants extend neurites in the presence of ECM.

\footnotetext{
* Current address: American Red Cross, J.H. Holland Cell Biology Laboratory, Rockville, MD 20855, U.S.A.

Correspondence: J.R. Wujek, Laboratory of Molecular Biology, National Institute of Neurological Disorders and Stroke, National Institutes of Health, Building 36, Room 3D-02, Bethesda, MD 20892, U.S.A.
} 
In previous studies attempting to determine which of the different molecular components of the ECM can induce neurite outgrowth, these molecules had been purified from more abundant non-neural sources and tested for their effect on neurite outgrowth. Fibronectin stimulated neurite outgrowth from neurons of the peripheral nervous system (PNS), but not from CNS neurons ${ }^{44}$. Collagen stimulated neurite outgrowth from dorsal root ganglion (DRG) cells of the chick and of PC12 cells ${ }^{7,8}$ but not from ciliary ganglion neurons of the chick $^{63}$. Laminin induced neurite outgrowth from all neurons tested ${ }^{2,19,36,44,57}$. Of particular importance to our work is laminin, which is a large $(900 \mathrm{kDa})$ glycoprotein of the $\mathrm{ECM}^{61}$. Studies using various cell types (teratocarcinoma cells, parietal endoderm cells, L6 myoblasts) and mouse embryos have shown that laminin consists of 3 polypeptide subunits: an A chain $(400 \mathrm{kDa})$, a $\mathrm{B} 1$ chain $(230 \mathrm{kDa})$ and a $\mathrm{B} 2$ chain $(220 \mathrm{kDa})$, which are linked by disulfide bonds in a cross-shaped structure ${ }^{60}$.

In this paper, we report that $\mathrm{PC} 12$ cells vigorously extended neurites when seeded on astrocyte ECM and that this effect was inhibited $50 \%$ by anti-laminin but not by anti-fibronectin ${ }^{68}$. Astrocytes have been reported to contain laminin $^{1,50}$ and fibronectin ${ }^{43}$, but not collagen ${ }^{45}$. Next, we investigated which laminin components were present in astrocytes because some cell types do not synthesize all 3 laminin subunits. For example, myoepithelial tumor cells, embryonic mouse muscle cells, and cultured Schwann cells produce the laminin B chain(s) but no detectable A chain ${ }^{9,13,28,66}$. In adult mouse tissues, there are considerable variations in the ratios of each laminin mRNA ${ }^{26}$. We have found, by an analysis of both laminin mRNA and protein, that cultured astrocytes synthesize only the $\mathrm{B} 2$ chain of laminin ${ }^{69}$. These results suggest that astroglial cells of the developing nervous system produce only B2-laminin, and that this component suffices to stimulate axonal growth.

\section{MATERIALS AND METHODS}

\section{Cell culture}

Primary cultures of astrocytes from the cerebral cortex of neonatal Sprague-Dawley rats, Wistar rats, and BALB/C mice were obtained as described by Estin and Vernadakis ${ }^{18}$. The cells were grown in Dulbecco's Modified Eagle Medium (DMEM) without glutamine but containing $10 \%$ fetal calf serum (FCS) (serumsupplemented medium) until the cells became confluent. Then the culture medium was changed to DMEM containing $10 \%$ dialyzed FCS in which D-valine was substituted for $\mathrm{L}$-valine to eliminate fibroblasts ${ }^{18.21}$. The astrocytes were maintained in culture flasks for periods of 5 days to 3 months. The astrocyte cultures were determined, by indirect immunofluorescence microscopy, to be greater than $95 \%$ positive for glial fibrillary acidic protein (GFAP; anti-GFAP generously provided by $\mathrm{Dr}$. L. Eng). Cells were incubated at $37{ }^{\circ} \mathrm{C}$ in $5 \% \mathrm{CO}_{2}$, and the medium was changed twice a week. Mouse F9 teratocarcinoma cells (from American Type Collection, CRL \#1720) were grown in DMEM plus $15 \%$ FCS and
$2 \mathrm{mM}$ glutamine. Laminin synthesis was induced by adding retinoic acid (100 nM) and dibutyryl cyclic adenosine monophosphate (1 $\mathrm{mM}$ ) to the F9 culture medium and grown for $\$ 7$ davs before protein or RNA extraction.

To isolate astrocyte ECM, the astrocytes were trypsinized, passaged into $35 \mathrm{~mm}$ Primaria culture dishes (Falcon) at $1 \times 10^{5}$ cells $/ \mathrm{cm}^{2}$ and incubated for $24 \mathrm{~h}$ in serum-supplemented medium. Using the method of Wujek and Akeson ${ }^{67}$, the astrocytes were incubated with $0.5 \%$ Triton $\mathrm{X}-100$ in phosphate-buffered saline $\left(0.9 \% \mathrm{NaCl}, 1.5 \mathrm{mM} \mathrm{KH}_{2} \mathrm{PO}_{4}\right.$ and $5.1 \mathrm{mM} \mathrm{NaH} \mathrm{PO}_{4}$ at $\mathrm{pH} 7.2 ; \mathrm{S}$ \& S Media, Inc., Rockville, MD), and then extensively rinsed with the phosphate-buffered saline alone. This treatment left a layer of ECM attached to the surface of the culture dish. For negative controls, Primaria dishes were incubated with serum-supplemented medium (no cells) for $24 \mathrm{~h}$, and treated the same as the experimental dishes.

Cerebral cortical explants, dissociated cerebellar granule neurons or $\mathrm{PC} 12$ cells were used to test for neurite growth-promoting activity of astrocyte ECM. Cerebral cortical explants were obtained from embryonic day 14 Sprague-Dawley rat fetuses according to the method of Oorschot and Jones ${ }^{42}$. Several explants $\left(1-2 \mathrm{~mm}^{3}\right)$ were placed into ECM-coated dishes or poly-1-lysine-coated dishes in a small volume of the N1 serum-free medium of Bottenstein and Sato ${ }^{4}$ containing $1 \%$ bovine serum albumin (serum-free medium). Dissociated cerebellar granule neurons were obtained from postnatal day 8 rat pups according to previously described methods ${ }^{32.59}$. Granule neurons were seeded at a density of $1 \times 10^{5} \mathrm{cells} / \mathrm{cm}^{2}$ into ECM-coated or poly-L-lysine coated dishes in serum-free medium. Cytosine arabinoside $\left(2 \times 10^{-5} \mathrm{M}\right)$ was added to cultures of cerebral cortex explants and cerebellar granule neurons to inhibit proliferation of non-neuronal cells. PC12 cells were seeded at a low density $\left(3 \times 10^{3}\right.$ cells $\left./ \mathrm{cm}^{2}\right)$ in dishes coated with astrocyte ECM or in uncoated dishes in serum-free medium.

Neurite outgrowth from $\mathrm{PC} 12$ cells was used to quantitate neurite-promoting activity of astrocyte ECM. The PC12 cells were not preincubated with nerve growth factor (NGF). After $24 \mathrm{~h}, \mathrm{PC1}$ cells with and without neurites were counted (a neurite was defined as a cytoplasmic extension that was at least as long as the diameter of one cell body; it usually had a swollen growth cone at its tip). The fraction of such neurite-containing cells was expressed as a percentage of the total number of PC12 cells. For negative controls, PC12 cells were seeded in dishes that had been incubated only with serum-supplemented medium. Positive controls were identical to negative controls except that $20 \mathrm{ng} / \mathrm{ml} \mathrm{NGF}$ (prepared from male mouse saliva according to the method of Burton et al. ${ }^{6}$ ) were added to the culture medium.

Anti-laminin antiserum was collected from rabbit that had been immunized with purified laminin (Bethesda Research Labs). Subsequently, anti-laminin immunoglobulins (IgG) were purified from the serum by affinity chromatography ${ }^{61}$, using immobilized laminin kindly provided by Dr. H. Kleinman (NIDR/NIH). Anti-fibronectin antiserum was obtained from Kirkegaard and Perry. Anti-NGF was the generous gift of Dr. J. Mill (NINDS/NIH). Pre-immune serum, from the same rabbits immunized with laminin, served as negative controls. Antisera, normal serum or IgG were diluted in serum-free medium and applied to astrocyte ECM-coated dishes. PC12 cells were then added to the culture dishes and neurite outgrowth was measured $24 \mathrm{~h}$ later.

\section{Protein immunoblots}

Astrocytes (4 weeks in culture) and differentiated F9 cells were washed twice with ice-cold Tris-buffered saline $(0.15 \mathrm{M} \mathrm{NaCl}$ and 25 $\mathrm{mM}$ Tris- $\mathrm{HCl}, \mathrm{pH} \mathrm{7.4)}$. Proteins were extracted by adding $1 \mathrm{ml}$ of hot sample buffer (2\% sodium dodecyl sulfate (SDS), $5 \% \beta$ mercaptoethanol, $10 \%$ glycerol, and $62.5 \mathrm{mM}$ Tris-HCl, $\mathrm{pH} 6.8$ ). The cell lysates were transferred to microcentrifuge tubes, boiled for $5 \mathrm{~min}$, and then centrifuged at $10,000 \mathrm{~g}$ for $10 \mathrm{~min}$ to remove insoluble material. The supernatant was saved at $-20{ }^{\circ} \mathrm{C}$ for analysis. Estimates of protein concentration were performed as described by Bradford 5 using a BioRad kit. Cellular proteins were 
electrophoresed on SDS-polyacrylamide linear gradient gels (4$12 \%$ ), and then transferred to nitrocellulose filters ${ }^{62}$. Immunoreactive protein bands were detected by incubation with rabbit antibodies against the individual laminin chains ${ }^{51}$ (diluted 1:800 or 1:1600). Anti-laminin immunoreactivity was visualized by incubation with alkaline phosphatase-conjugated anti-rabbit IgG and color development according to the supplier's instructions (Promega).

\section{RNA analysis}

Primary cultures of astrocytes were grown for specified periods of time, then passaged into $75 \mathrm{~cm}^{2}$ culture flasks at a density of $1 \times$ $10^{5} \mathrm{cells} / \mathrm{cm}^{2}$ and incubated for $24 \mathrm{~h}$. Total RNA was isolated from astrocytes and from differentiated and undifferentiated F9 cells, using the standard guanidinium isothiocyanate/cesium chloride (GTC) method ${ }^{12}$. In this procedure, cultured cells were directly lysed in GTC solution, then homogenized with a Polytron homogenizer. The homogenate was layered onto a $\mathrm{CsCl}$ solution in a centrifuge tube and centrifuged overnight at $170,000 \mathrm{~g}$. The RNA pellet was resuspended in $7.5 \mathrm{M}$ guanidine- $\mathrm{HCl}$, extracted with phenol/chloroform (1:1) and then precipitated with ethanol. This pellet was resuspended in diethyl pyrocarbonate-treated water and reprecipitated with ethanol. The purified RNA was dissolved in diethyl pyrocarbonate-treated water and stored at $-70^{\circ} \mathrm{C}$.

Aliquots of total RNA $(10 \mu \mathrm{g})$ were loaded on a denaturing $0.9 \%$ agarose $18 \%$ formaldehyde gel with $0.02 \mathrm{M}$ MOPS (3-[ $\mathrm{N}$-morpholino]propanesulfonic acid) buffer and electrophoresed at $25 \mathrm{~V}$ for $16-20 \mathrm{~h}$. The RNA was transferred to a nitrocellulose filter by passive diffusion. Two cDNA probes for the $A$ chain were used: clone PAO3, which codes for the $5^{\prime}$ end of the mRNA, and PAO5, which codes for the $3^{\prime}$ end $^{48}$. The clones for the B1 chain (PBI; a $300 \mathrm{bp}$, Hind III-Hla I fragment from P24 cloned into PUC19 vector) and for the $\mathrm{B} 2$ chain (P7) both code for the $3^{\prime}$ end of the $\mathrm{mRNA}^{47,49}$. The probes were radioactively labelled with $\left[{ }^{32} \mathrm{P}\right] \mathrm{dCTP}$ by random primer labelling. The filters were hybridized with the cDNA probes $\left(25 \mathrm{ng} ; 10^{7} \mathrm{cpm}\right.$ ) at $50^{\circ} \mathrm{C}$ for $24 \mathrm{~h}$ in hybridization buffer ( $50 \%$ formamide; $50 \mathrm{mM}$ sodium phosphate, $\mathrm{pH} 6.5 ; 5 \times$ sodium chloride/sodium citrate (SSC) buffer; $0.2 \%$ SDS; $1 \mathrm{mM}$ ethylenediamine tetraacetic acid; $0.05 \%$ Ficoll; $0.05 \%$ polyvinylpyrrolidone; and $200 \mu \mathrm{g} / \mathrm{ml}$ denatured salmon DNA), then washed at $65^{\circ} \mathrm{C}$ with $0.1 \times$ SSC and $0.5 \%$ SDS, dried, and exposed to Kodak $X$ OMAT-AR X-ray film at $-70^{\circ} \mathrm{C}$. In addition, several filters were washed at low stringency $\left(2 \times \mathrm{SSC} / 1 \% \mathrm{SDS}\right.$ at $\left.50^{\circ} \mathrm{C}\right)$.

Quantities of mRNA were measured by optical scanning of autoradiograms (Zeineh soft laser scanning densitometer; Biomed Instruments, Inc.). To correct for possible variations in total RNA quantities, the blots were rehybridized with a cDNA probe for cyclophyllin, a protein produced in constant amounts ${ }^{11}$. The autoradiograms were scanned again, and the RNA values expressed as a ratio of the OD of laminin to cyclophyllin mRNA.

\section{RESULTS}

\section{CNS neurons extend neurites on the extracellular matrix of astrocytes}

Cerebellar granule neurons were dissociated from 8-day-old rat pups and seeded onto astrocyte ECM as described in Materials and Methods. Within $24 \mathrm{~h}$, the neurons had attached to the substrate in clumps and extended many neurites (Fig. 1A). During the next 2-4 days, the neurites extensively elongated and later branched. Long, thick fascicles of neurites were often seen to connect neighboring cell clumps.

Some neurite outgrowth from granule neurons was also observed on poly-L-lysine-coated dishes; the granule neurons tended to attach singly or in small clumps of cells
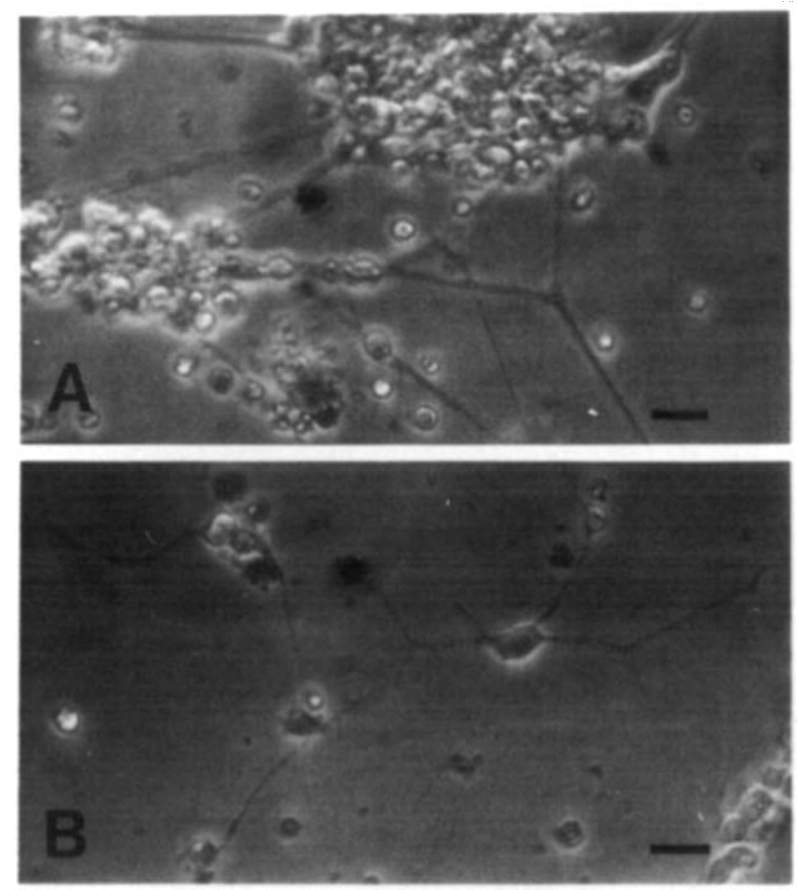

Fig. 1. Neurite outgrowth from cerebellar granule neurons $24 \mathrm{~h}$ after being seeded onto astrocyte ECM or poly-L-lysine. A: neurons on ECM that had been derived from astrocytes grown 3 weeks in culture. B: neurons on poly-L-lysine. Bar $=20 \mu \mathrm{m}$.

(Fig. 1B). In contrast to the pattern of neurite outgrowth on astrocyte ECM, the neurites on poly-L-lysine tended to elongate as thin fibers (possibly as individual neurites) with numerous branches along their length.

To examine neurite outgrowth from cortical neurons, small cubes $\left(1-2 \mathrm{~mm}^{3}\right)$ of cerebral cortex were obtained from rat embryos (day 14 of gestation) and placed onto astrocyte ECM- or poly-L-lysine-coated dishes. A variable number of explants dislodged from the substrate and floated in the culture medium. For the attached explants, the extent of neurite outgrowth was minimal after $24 \mathrm{~h}$ regardless of substrate. But after 2 days in vitro, extensive neurite outgrowth was observed on astrocyte ECM (Fig. 2A,B). Numerous large fascicles of neurites extended from the explants; these fascicles then broke up into small fascicles and finally became thin fibers that were extensively branched with growth cones at their tips (Fig. 2B). In contrast, little or no neurite outgrowth was evident from explants attached on the poly-L-lysine substrate (Fig. 2C).

\section{Anti-laminin inhibits neurite outgrowth on astrocyte ECM}

Polyclonal antibodies against laminin, fibronectin, and NGF were used in a neurite outgrowth inhibition assay to determine the molecular type(s) of neurite outgrowthpromoting factor within astrocyte ECM. To measure inhibition of neurite outgrowth, PC12 cells were used instead of primary neurons because they uniformly attached to the substrate and extended neurites in an 

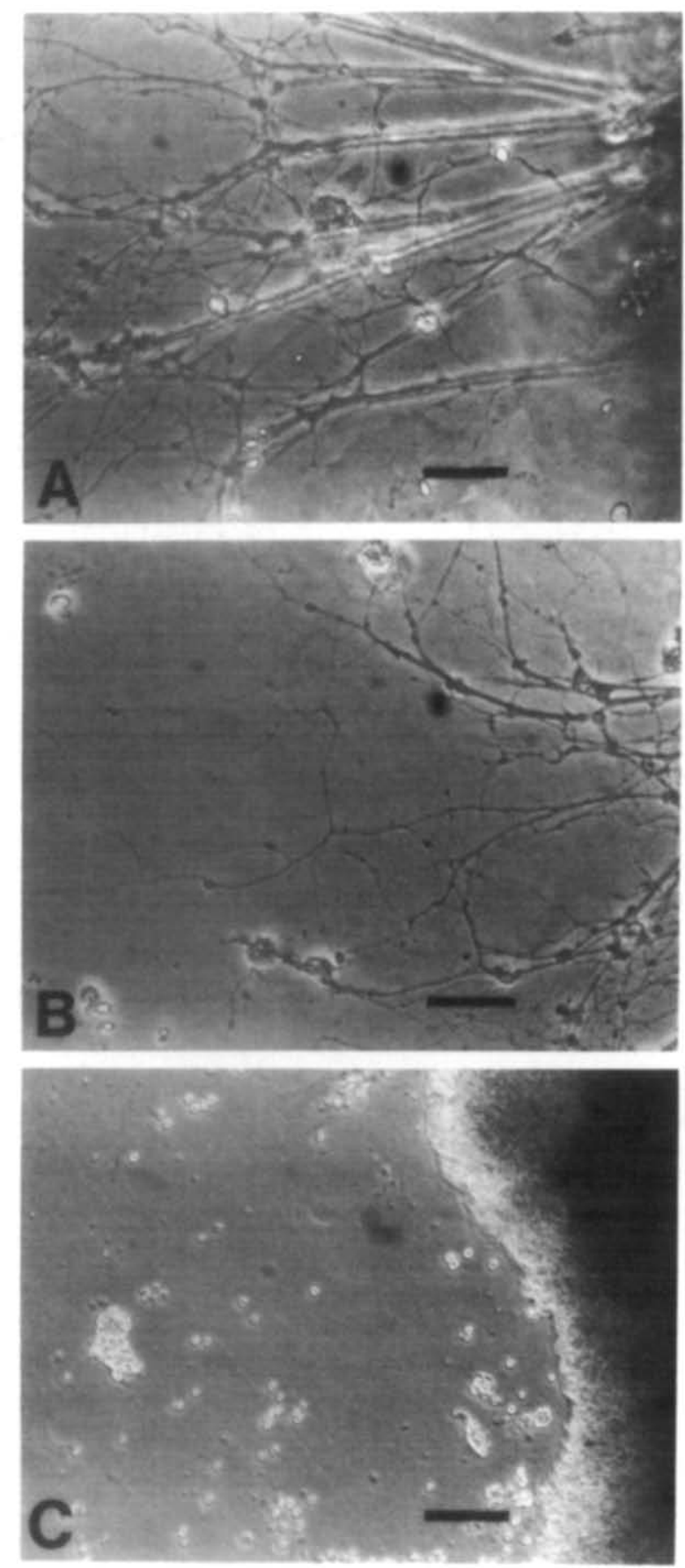

Fig. 2. Cerebral cortex explants (embryonic day 14) after 4 days on astrocyte ECM or poly-L-lysine. A: explant on ECM derived from astrocytes grown 3 weeks in culture. This view illustrates neurite fascicles as they emerge from the explant. B: tips of neurites distant from explant on astrocyte ECM. C: explant on poly-1-lysine. Bar = $20 \mu \mathrm{m}$

'all-or-none' manner that was readily quantifiable.

Antibody cross-reactivity was tested by immunoblotting against purified laminin, fibronectin, collagen and NGF. Strong immunoreactivity was observed with laminin, whereas no reactivity was visible with fibronectin or collagen (data not shown).
Antibodies were diluted 1:400 in serum-free culture medium and applied onto the astrocyte ECM $20 \mathrm{~min}$ before the PC12 cells were seeded. Fig. 3 demonstrates the effect on neurite outgrowth after $24 \mathrm{~h}$. Addition of normal rabbit serum (Fig. 3A) or normal goat serum (data not shown) had no apparent effect on neurite outgrowth from PC1 2 cells. Numerous neurites, which are several cell body diameters long and tipped with bulbous growth cones, extended from the cell bodies. Anti-laminin antibodies (Fig. 3B) reduced the number of $\mathrm{PC} 12$ cells that exhibited neurites. The number of $\mathrm{PC} 12$ cells appeared greater in the presence of anti-laminin than in the presence of the other sera. Since the stimulation of neurite outgrowth in $\mathrm{PC} 12$ celis stops their proliferation, it is likely that the inhibition of neurite outgrowth by anti-laminin causes renewed cell proliferation.

Quantitative measurements demonstrated a reduction of neurite outgrowth by approximately $50 \%$ (Fig. 4). The length of neurites appeared shorter in the presence of anti-laminin antibodies than in the presence of normal rabbit serum. Addition of anti-fibronectin (Figs. 3C; and 4) or anti-NGF antibodies (Figs. 3D and 4) had no visible effects on neurite outgrowth from PC12 cells.

We attempted to achieve complete inhibition of neurite outgrowth by increasing the antibody concentration. However, this resulted in greater inhibition by the normal serum as well as by the anti-laminin antibody. In a previous study of neurite outgrowth, serum had been shown to non-specifically inhibit neurite outgrowth ${ }^{56}$. To rule out any non-specific serum effect, we repeated the experiment using normal IgG and affinity-purified antilaminin IgG. Fig. 5 illustrates that 5 and $10 \mu \mathrm{g} / \mathrm{ml}$ of the purified anti-laminin inhibited neurite outgrowth whereas the normal rabbit IgG showed little or no inhibition. However, the increased amount of anti-laminin still produced only about $50 \%$ inhibition.

\section{ECM neurite growth-promoting activity increases as astro- cytes mature in vitro}

We tested whether the neurite-promoting activity of astrocyte ECM changed when primary astrocytes were grown for extended time periods in vitro. Astrocyte cultures were established from neonatal rats and grown for 1, 2, 3, 4 and 12 weeks in culture flasks. At these times, the astrocytes were trypsinized, passaged into 35 $\mathrm{mm}$ Primaria dishes $\left(1 \times 10^{5}\right.$ cells $\left./ \mathrm{cm}^{2}\right)$ and incubated for $24 \mathrm{~h}$ to produce fresh ECM. PC12 cells were then seeded onto the ECM and neurite outgrowth was measured. At each time point, astrocyte ECM stimulated neurite outgrowth to some extent, but the activity increased two-fold when the astrocytes had grown for more than 2 weeks in vitro (Fig. 6). Apparently, the older astrocytes 

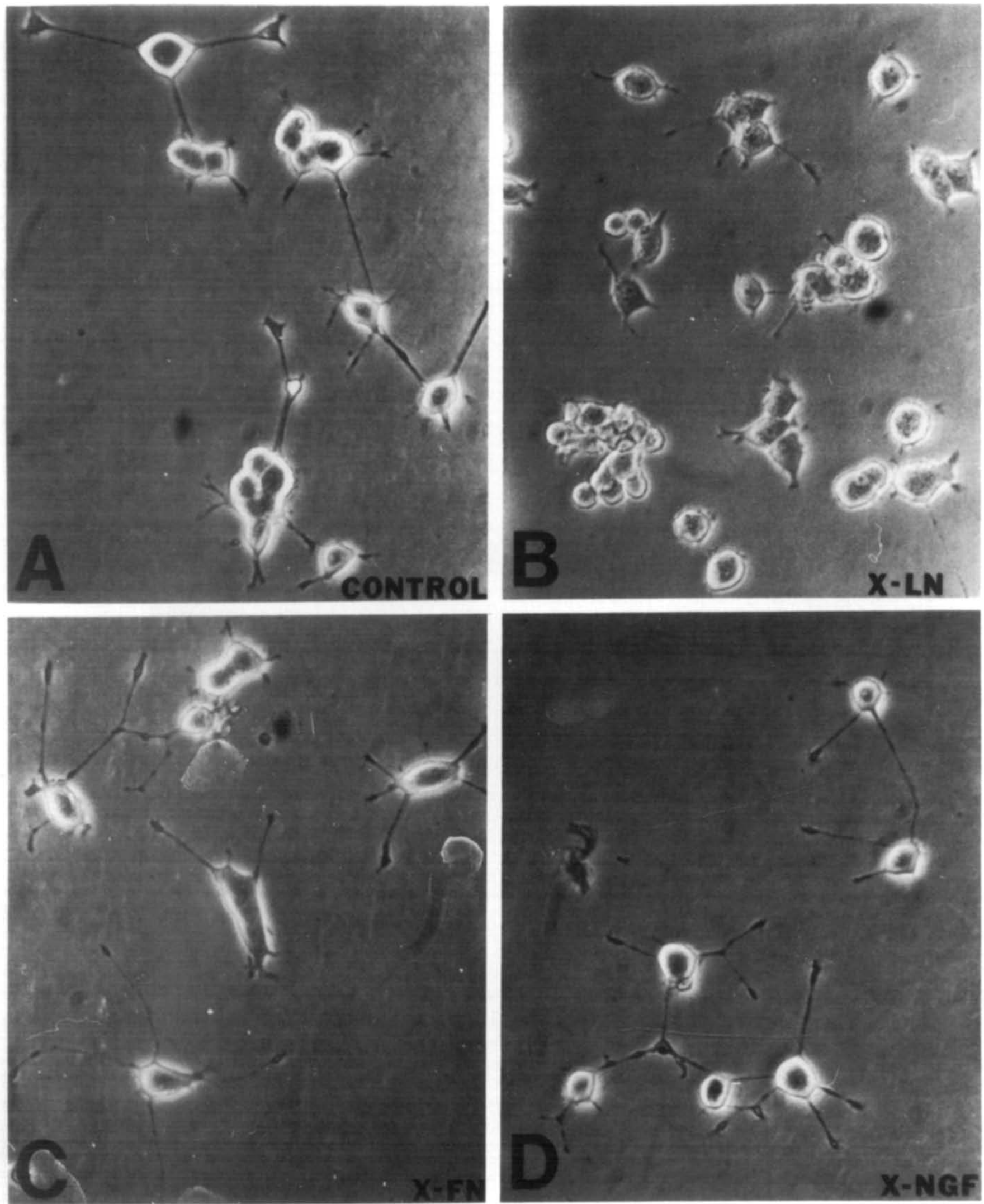

Fig. 3. Antibody inhibition of neurite outgrowth from PC 12 cells after $24 \mathrm{~h}$ on astrocyte ECM. All antisera or non-immune sera were added to culture medium at a final dilution of 1:400 prior to seeding PC12 cells onto the substrate. A: negative control: pre-immune rabbit serum. B: rabbit anti-laminin (X-LN). Note the reduction of numbers of PC12 cells with neurites as well as the decrease in length of the neurites. C: goat anti-fibronectin (X-FN). D: rabbit anti-nerve growth factor (X-NGF). Bar $=20 \mu \mathrm{m}$. 


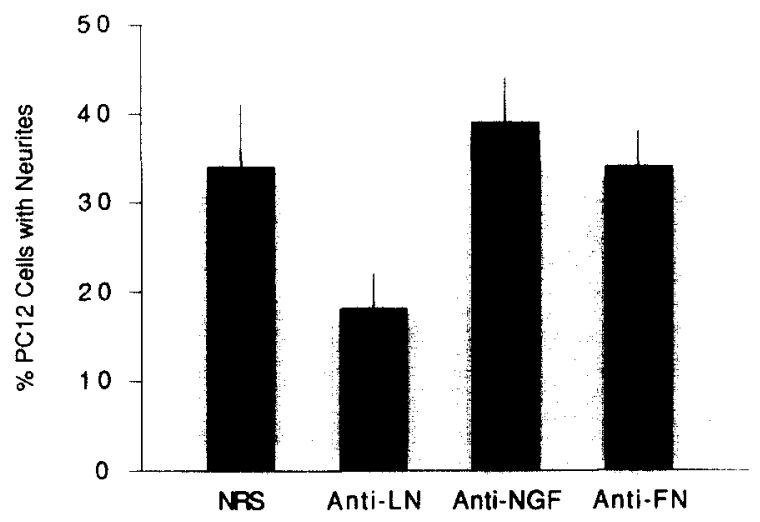

Fig. 4. Quantitative analysis of antibody inhibition of neurite outgrowth from $\mathrm{PC1} 2$ cells using antiserum. NRS, pre-immune rabbit serum; Anti-LN, anti-laminin antiserum; Anti-NGF, antinerve growth factor antiserum; Anti-FN, anti-fibronectin antiserum. Final dilution of all antisera of pre-immune sera was 1:400. Error bars represent standard deviation.

synthesized neurite growth-promoting factor at a greater rate than the younger astrocytes.

\section{Astrocytes synthesize only the laminin B2 chain}

Analysis of astrocyte proteins by immunoblotting with laminin chain-specific antibodies revealed that only the B2 chain of laminin was synthesized by cultured astrocytes. Cellular proteins extracted from astrocytes (4 weeks in culture) and from differentiated F9 cells were electrophoresed and transferred to a nitrocellulose filter. The filter was cut into 3 strips and each strip was incubated with laminin chain-specific antibody ${ }^{51}$.

The cultured astrocytes exhibited a polypeptide band that was immunoreactive with the anti B2-laminin but no immunoreactivity appeared with the anti-A chain or with

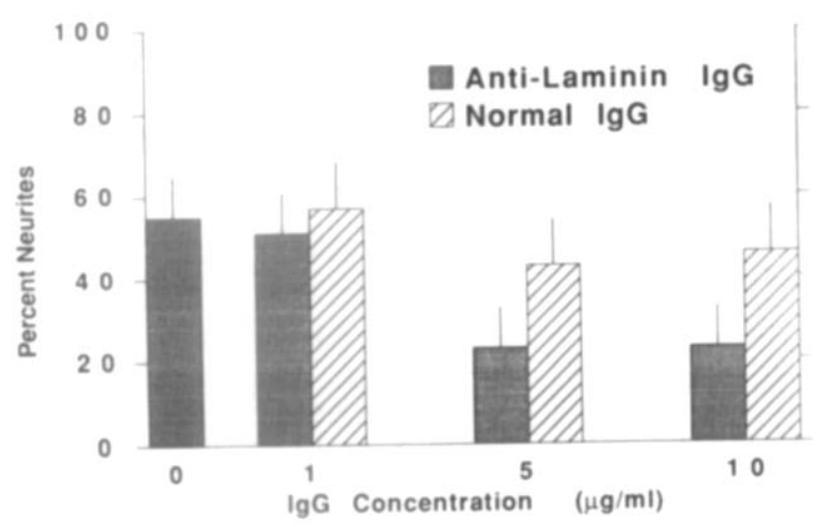

Fig. 5. Quantitative analysis of antibody inhibition of neurite outgrowth from $\mathrm{PC} 12$ cells using normal rabbit IgG or affinitypurified anti-laminin IgG. Error bars represent standard deviation. The differences between anti-laminin IgG and normal rabbit IgG at $5 \mu \mathrm{g} / \mathrm{ml}$ and at $10 \mu \mathrm{g} / \mathrm{ml}$ were statistically significant by Student's $t$-test (99\% confidence level).

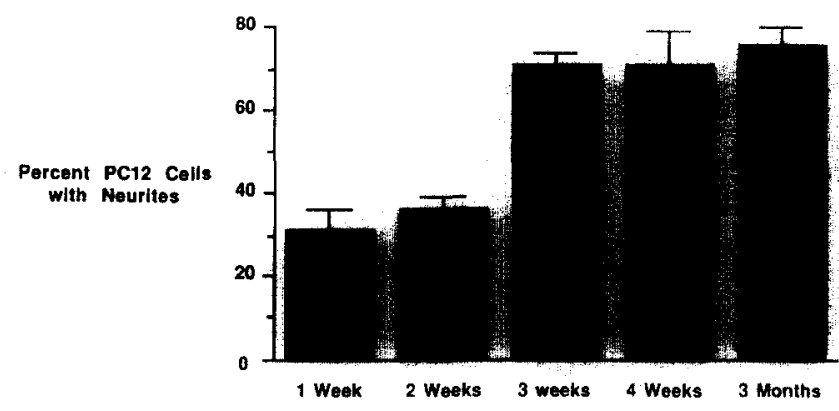

Fig. 6. Neurite growth-promoting activity of astrocyte ECM as a function of time in vitro. Astrocytes were cultured for 1-12 weeks, then passaged into test dishes $\left(1 \times 10^{5} \mathrm{cells} / \mathrm{cm}^{2}\right)$ and incubated for $24 \mathrm{~h}$. Cells were removed from the dish (see Materials and Methods), leaving a layer of ECM. Neurite outgrowth was measured as the percentage of $\mathrm{PC} 12$ cells possessing neurites.

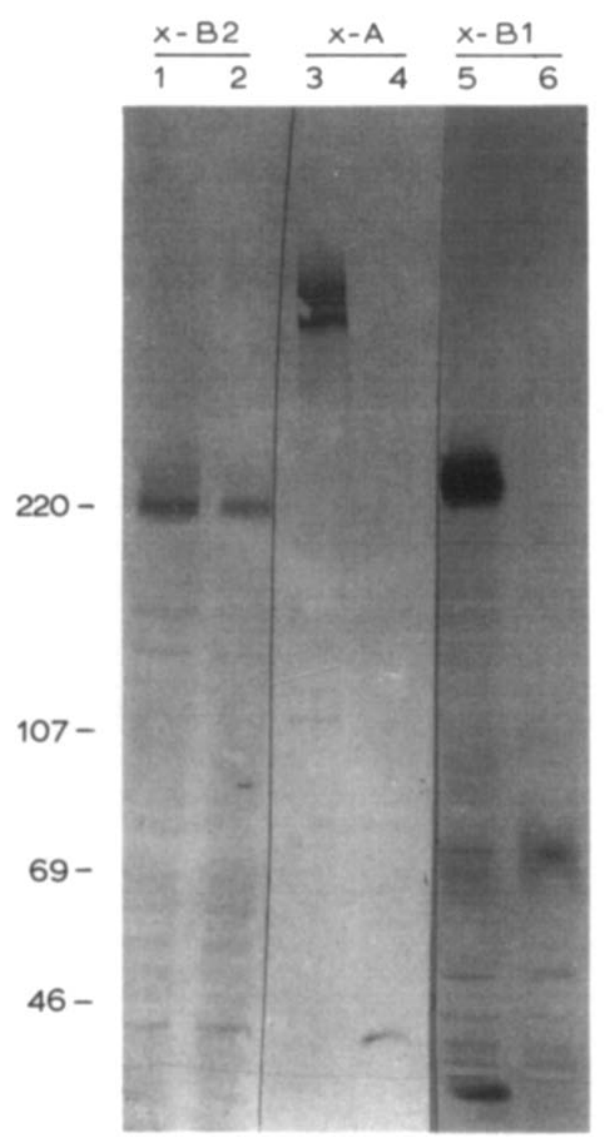

Fig. 7. Protein immunoblot of cell lysates from differentiated F9 cells (lanes 1,3 and 5) and from astrocytes (lanes 2, 4 and 6). F9 cell proteins $(15 \mu \mathrm{g})$ and astrocyte protein $(100 \mu \mathrm{g})$ were electrophoresed (SDS-PAGE; 4-12\% gradient) under reducing conditions and transferred to a nitrocellulose filter. The filter was cut into 3 strips and incubated with anti-B2 laminin $(1: 800)$, anti-A laminin $(1: 800)$ or anti-B1 laminin $(1: 1600)$. Astrocytes exhibited an immunoreactive polypeptide band with anti-B2 (lane 2), but no bands appeared with anti-A (lane 4) or anti-B1 (lane 6). F9 cells showed immunoreactivity with all 3 chain-specific antibodies (lanes $1,3$ and 5$)$. Molecular weight standards $(\times 1000)$ are indicated on the left-hand side. 


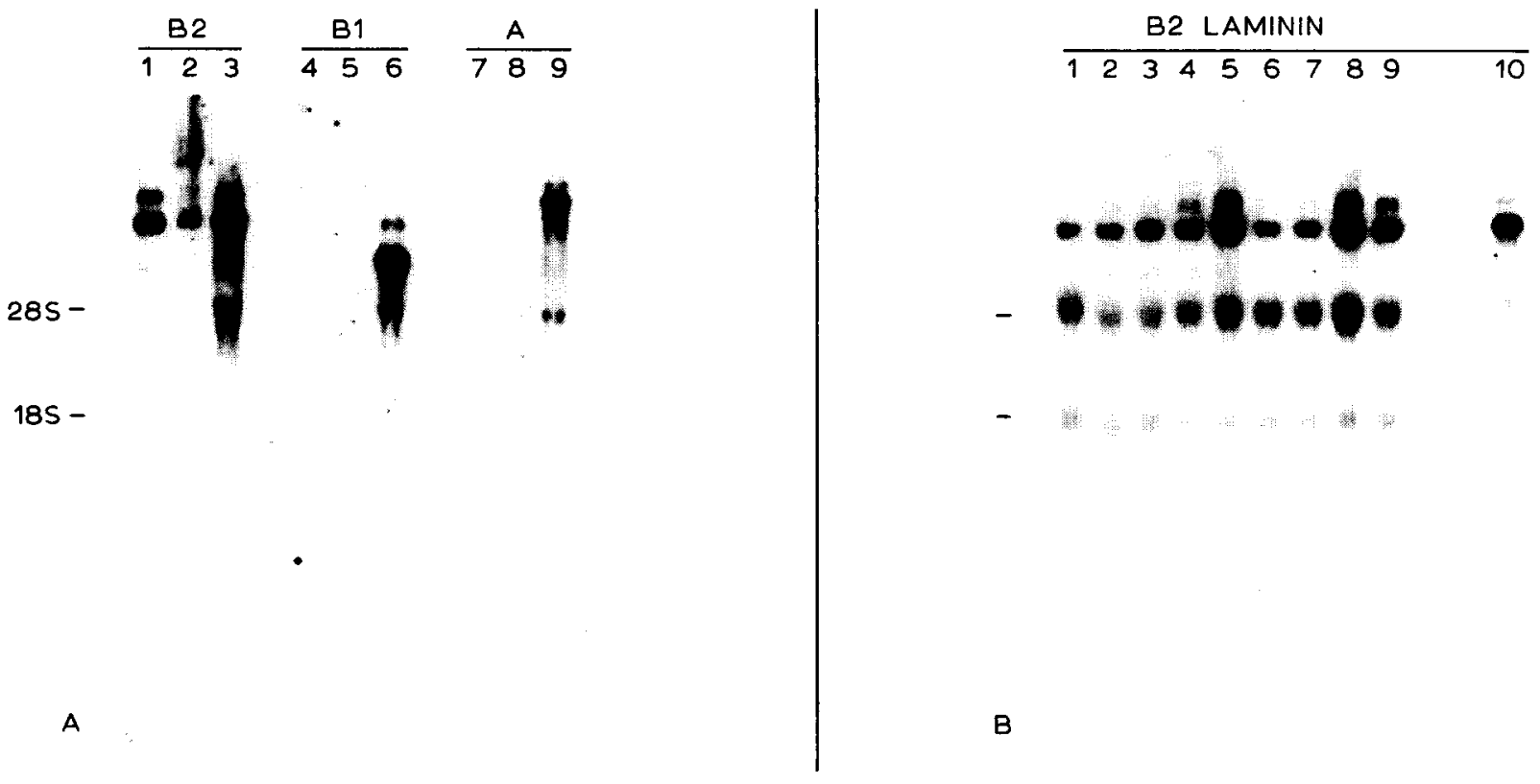

Fig. 8. A: Northern blot of RNA from cultured mouse astrocytes (lanes 1, 4 and 7), rat astrocytes (lanes 2, 5 and 8) and differentiated F9 teratocarcinoma cells (lanes 3,6 and 9). Lanes 1-3 were hybridized with B2 chain cDNA probe (P7), lanes 4-6 were hybridized with a B1 chain cDNA probe (PBI) and lanes 7-9 were hybridized with an A chain cDNA probe (PA03). The F9 cells exhibit mRNA for all 3 chains of laminin (A, B1, B2), whereas the astrocytes exhibit mRNA only for the B2 chain of laminin. B: Northern blot of total RNA from rat and mouse astrocytes and from mouse F9 teratocarcinoma cells hybridized with a B2 chain cDNA probe (P7). Lanes 1-5: Sprague-Dawley rat astrocytes grown for 1, 2, 4,6 and 10 weeks in culture, respectively. Lanes 6 and 7: Wistar rat astrocytes grown for 4 and 6 weeks in culture, respectively. Lane 8: Sprague-Dawley rat astrocytes in serum-free medium. Cells had been grown 20 days in serum-supplemented medium, then passaged and grown $24 \mathrm{~h}$ in serum-free medium. Lane 9: BALB/C mouse astrocyte RNA ( 3 weeks in culture). Lane 10: mouse F9 embryocarcinoma cell RNA. Position of $28 \mathrm{~S}$ and $18 \mathrm{~S}$ ribosomal RNA is marked on left-hand side.

the anti-B1 chain antibodies (Fig. 7; lanes 2, 4 and 6). Differentiated F9 teratocarcinoma cells (see Materials and Methods) served as a positive control, since these cells synthesize all 3 laminin chains ${ }^{60}$. These cells exhibited immunoreactivity with each of the laminin chainspecific antibodies (Fig. 7; lanes 1, 3 and 5).

RNA blot hybridization was carried out to identify laminin mRNA transcripts in cultured mammalian astrocytes. The blots were hybridized with cDNA probes for the $\mathrm{A}, \mathrm{B} 1$, and $\mathrm{B} 2$ chains of $\operatorname{laminin}^{47-49}$. RNA from

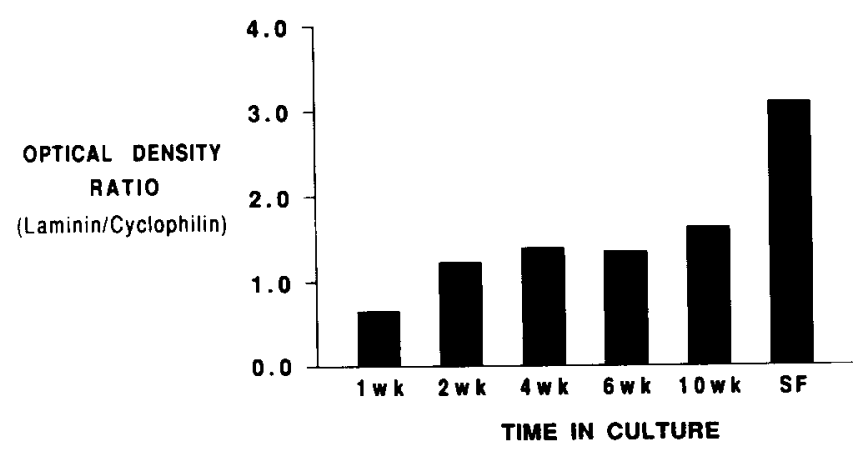

Fig. 9. Quantitative analysis of laminin B2 and cyclophilin mRNA levels in cultured rat Sprague-Dawley astrocytes as measured by optical density scanning of autoradiograms. SF, serum-free medium ( 3 weeks in culture). differentiated F9 teratocarcinoma cells, which abundantly express all laminin chains, served as a positive control. As shown in Fig. 8A (lanes 3,6 and 9), the F9 cells produced mRNA for the B2, B1 and A chains of laminin. In contrast, cultured rat astrocytes synthesized mRNA for B2 laminin (Fig. 8A, lane 2), but not for B1 or A laminin (Fig. 8A, lanes 5 and 8 ). To test whether this result was unique to astrocytes from SpragueDawley rats, we also probed RNA from Wistar rat (data not shown) and BALB/C mouse astrocytes. Again, we found only B2 laminin (Fig. 8A, lanes 1, 4 and 7). Even when the filters were washed at low stringency (see Materials and Methods), we did not observe hybridization of the A or B1 laminin cDNA probes with astrocyte RNA (data not shown).

We also examined the production of $\mathrm{B} 2$ laminin mRNA by astrocytes as a function of time in culture (Fig. $8 \mathrm{~B}$, lanes 1-5). When the same amount of total RNA was applied to each lane of the agarose gel, the amount of B2 laminin (measured by scanning autoradiograms) was relatively low at 1 week in culture, increased after 2 weeks, and continued to increase up to 10 weeks in culture (the longest time examined). The quantitative analysis (Fig. 9) verified the visual observations.

The effect of astrocyte growth in a serum-free, chemically defined culture medium was also tested. After 
20 days in serum-supplemented medium, the astrocytes were passaged into new flasks and grown for $24 \mathrm{~h}$ in serum-free medium. Again, only B2 laminin mRNA was formed and its level was almost twice that observed with serum-supplemented cultures of the same age (Fig. 8B, lane 8; Fig. 9); it approached the mRNA levels found in serum-supplemented cultures of 10 weeks.

\section{DISCUSSION}

We have examined the neurite outgrowth from 3 types of neuronal cells on the ECM obtained from cortical astrocytes. The astrocyte ECM was newly secreted (within $24 \mathrm{~h}$ ) and anchored to the tissue culture dishes. Previous work has shown that neurons derived from the PNS vigorously extend neurites on cultured astrocytes ${ }^{1}$ ${ }^{62,63}$ or on astrocyte $\mathrm{ECM}^{67}$. CNS neurons also exhibit neurite outgrowth on cultured astrocytes ${ }^{20,40}$. We have extended these findings by demonstrating that astrocyte ECM can stimulate neurite outgrowth from cerebellar granule neurons and cerebral cortex explants.

Astrocytes secrete the ECM components fibronectin and laminin and heparan sulfate proteoglycan ${ }^{1,43,50}$. Collagen found in the ECM of other cell types, such as Schwann, endothelial, and fibroblast $3 T 3$ cells $^{3,10,22,65}$ has not been described for astrocyte ECM.

Our antibody studies with anti-fibronectin, anti-nerve growth factor and anti-laminin antiserum showed inhibition of neurite outgrowth on astrocyte ECM only with the latter. The failure of anti-NGF to inhibit neurite outgrowth on astrocyte ECM suggests that a neurite outgrowth-promoting mechanism exists in PC12 cells different from the NGF-stimulating mechanism. The antilaminin did not completely block neurite outgrowth, which might have been due to insufficient amounts of antiserum. However, attempts to increase the quantity of antibody led to non-specific inhibition, as seen by the almost complete inhibition of neurite extension with normal rabbit serum. This could be similar to the non-specific inhibition of neurite outgrowth observed with fetal calf serum ${ }^{56}$. To eliminate the non-specific effect, the neurite inhibition experiments were repeated with affinity-purified fractions of anti-laminin IgG. Increasing the amount of anti-laminin IgG still produced a maximum of $50 \%$ inhibition. Therefore, the astrocyte ECM may contain other neurite growth-promoting factors.

We have used laminin cDNA probes and chain-specific laminin antibodies (developed from the EHS tumor) to investigate the synthesis of laminin mRNA and protein by cultured cerebral cortex astrocytes. Our results indicated that cultured astrocytes synthesize only the $\mathrm{B} 2$ laminin subunit. This finding contrasts with the work of Selak et al.$^{50}$, who claimed that astrocytes synthesized all
3 laminin subunits. The higher molecular weight protein immunoprecipitated with anti-laminin by Selak et al. ${ }^{50}$ (see Fig. 4) probably corresponds to the $>250 \mathrm{kDa}$ protein immunoprecipitated by Cornbrooks et al." (see Fig. $3 \mathrm{~g}$ ). Since other ECM proteins (e.g. collagen IV and entactin) can be immunoprecipitated as part of a polypeptide complex, it is quite possible that the high molecular weight protein immunoprecipitated by Selak et al. ${ }^{50}$ and Cornbrooks et al. ${ }^{9}$ is not the $400 \mathrm{kDa}$ laminin A chain.

Recently, McLoon et al ${ }^{39}$ demonstrated that the optic nerve of the developing rat exhibited the $B$ chain(s) of laminin, but not the A chain. Also, Mattiessen et al. ${ }^{38}$ showed that conditioned medium from cortical astrocytes contained the B chain(s) of laminin, but not the A chain. In both cases, the workers used immunoblotting with polyclonal antibodies against the whole laminin molecule, but were not able to distinguish between the $\mathrm{B} 1$ and B2 chains of laminin. In another study ${ }^{35}$, RNA hybridization with cDNA probes for the individual laminin chains indicated that mRNA transcripts for both B1 and B2 laminin were present in embryonic mouse brain. However, the use of brain tissue as a source of RNA in those experiments precluded an unequivocal determination of the cell type producing the laminin mRNA.

We have carried out immunoblotting (with laminin chain-specific antibodies) and Northern hybridization analyses of protein and mRNA extracted from purified cultures of cortical astrocytes. Thus, we confirmed that astrocytes do not synthesize the laminin A chain. Furthermore, we extended the previous findings by demonstrating that cultured cortical astrocytes synthesize only the B2 chain and not the B1 chain of laminin.

Recent work $^{17,25}$ has indicated that laminin may represent a family of genes that extends beyond the genes of the 3 EHS tumor laminin chains. Hunter et al. ${ }^{25}$ have demonstrated a novel laminin-like protein concentrated in the synaptic cleft of the neuromuscular junction which they have called s-laminin. In addition, Leivo and Engval ${ }^{29}$ have identified a new laminin-like basement membrane protein, which they called merosin. Apparently, merosin possesses laminin B1 and B2 chains identical to that of the EHS tumor laminin ${ }^{17}$, but the third chain has a molecular weight of $300 \mathrm{kDa}^{15}$ (references in Leivo et al. ${ }^{30}$ ).

Possibly, the astrocytes are synthesizing their own variant of laminin which consists of more than just the B2 chain. The merosin variant of laminin exhibits $40 \%$ sequence identity with the EHS tumor A chain of laminin ${ }^{17}$. With $40 \%$ sequence identity between merosin and $\mathrm{A}$ chain $^{30}$, it seems likely that at least one of the EHS tumor cDNA probes for the A chain that we used would have recognized astrocyte mRNA that encodes for 
merosin. However, it remains possible that astrocytes produce a merosin-like laminin A chain sufficiently different that it is not recognized by EHS tumor cDNA probes. Such a molecule may form part of the astrocyte laminin and contribute to its neurite growth-promoting activity. Using a cDNA probe to s-laminin (generously supplied by J. Sanes), we have obtained preliminary evidence that cultured astrocytes synthesize mRNA for s-laminin (unpublished observations). This astrocyte mRNA transcript appears to have the same molecular weight as the EHS tumor B1 laminin mRNA. As described by Hunter et al. ${ }^{25}$, the s-laminin is most similar to the B1 chain and less like the B2 and A chains of laminin. Although neurons adhered strongly to substrates coated with the s-laminin protein, no neurite outgrowth was described ${ }^{25}$. Recent work by Ogawa et al. ${ }^{41}$ found no neurite outgrowth-promoting activity on substrates coated with purified recombinant B1 laminin chain. This would suggest that, although the astrocytes may make a B1-like laminin chain (i.e. s-laminin), the neurite outgrowth-promoting activity of the astrocyte laminin resides within the $\mathbf{B} 2$ chain.

Studies using proteolytic fragments of laminin ${ }^{14}$ and monoclonal antibodies to laminin fragments ${ }^{16}$ have localized the neurite-growth promoting site to the long arm of the laminin molecule. Since the long arm of laminin consists of a portion of all 3 laminin subunits bound together by sulfide bonds ${ }^{60}$, these experiments do not determine whether the neurite growth-promoting site is to be found on one, two or all 3 subunits. More recent experiments have shown that peptides derived from either the A chain or the $\mathrm{B} 2$ chain of laminin have neurite growth-promoting activity ${ }^{36,58}$, whereas purified recombinant B1 laminin subunit protein did not exhibit neurite growth-promoting activity ${ }^{41}$. In addition, mutations affecting the B2 laminin chain gene in Caenorhabditis elegans were found to cause misguided axonal growth ${ }^{23}$. (E. Hedgecock, personal communication).

These results suggest that all 3 chains together are not required for neurite growth-promoting activity. Furthermore, the A chain and the B2 chain (but not the B1 chain), together or separately, may suffice to stimulate neurite outgrowth. In particular, the demonstration that a B2 laminin peptide stimulates neurite outgrowth ${ }^{36}$ supports our hypothesis that the B2 laminin is responsible for the neurite outgrowth-promoting activity of astrocyte ECM.

\section{REFERENCES}

1 Ard, M.D. and Bunge, R.P., Heparan sulfate proteoglycan and laminin immunoreactivity on cultured astrocytes: relationship to differentiation and neurite growth, $J$. Neurosci., 8 (1988) 2844-2858.
To examine the question of developmental regulation, we measured neurite growth-promoting activity in astrocyte ECM as a function of time in culture. The possibility of using the maturation of astrocytes in vitro as a model for development in vivo has been demonstrated by others. The developmental profile of glutamate synthetase, S-100 protein and glial fibrillary acidic protein content of astrocytes in vivo corresponds to that found in brain tissue in vivo ${ }^{24,46}$. We observed that the neurite growth-promoting activity of astrocyte ECM increased as the astrocytes matured in culture. At all time points, the astrocyte cell density as well as the incubation time of reseeded astrocytes were held constant. Thus, the only major variable was the age of the astrocytes in vitro. The increased neurite growth-promoting activity suggests an enhanced rate of ECM synthesis by the older astrocytes.

However, these results contrasted with immunohistochemical studies which showed laminin immunoreactivity only within the prenatal mouse brain ${ }^{31,33,39}$. Within postnatal brain (which corresponded to the in vitro time frame of our studies) laminin disappeared from the brain parenchyma, although it was still found restricted to the meninges and blood vessels. In addition, primary astrocytes maintained in culture without passaging for periods of 1-28 days, exhibited laminin immunoreactivity for the first 12 days, and decreased thereafter ${ }^{34}$. Since the appearance of laminin immuno-reactivity was greatest shortly after dissociation and seeding the astrocytes ${ }^{34}$, the laminin production that we observed by mature astrocytes in vitro following trypsinization and passage into new culture dishes may mimic the reaction of astrocytes to acute injury.

In summary, we have shown that ECM deposited by cultured astrocytes stimulated neurite outgrowth from two types of CNS neurons. The inhibition of this neurite outgrowth by anti-laminin demonstrated that laminin was responsible for a large proportion of the neurite outgrowth-promoting activity exhibited by astrocyte ECM. Furthermore, the laminin that had been synthesized by the astrocytes was composed of only the B2 subunit. Taken together, these results suggest that B2 laminin suffices to stimulate neurite outgrowth, and that radial glial cells within the embryonic CNS may synthesize and secrete only the B2 laminin to stimulate axonal growth.

Acknowledgements. We thank Adele Cooney for assistance in preparing primary cultures of cerebellar granule neurons and Devera Schoenberg for preparing the manuscript.

2 Baron-Van Evercooren, A., Kleinman, H.K., Ohno, S., Marangos, P., Schwartz, J.P. and Dubois-Dalcq, M.E., Nerve growth factor, laminin and fibronectin promote neurite growth in human fetal sensory ganglia cultures, J. Neurosci. Res., (1982) $179-193$.

3 Baron-Van Evercooren, A., Gansmuller, A., Gumpel, M., 
Baumann, N. and Kleinman, H.K., Schwann cell differentiation in vitro: extracellular matrix deposition and interaction, Dev. Neurosci., 8 (1986) 182-196.

4 Bottenstein, J.E. and Sato, G.H., Growth of a rat neuroblastoma cell line in serum-free supplemented media, Proc. Natl. Acad. Sci. U.S.A., 76 (1979) 514-517.

5 Bradford, M.M., A rapid and sensitive method for the quantitation of microgram quantities of protein using the principle of protein dye binding, Anal. Biochem., 72 (1976) 248-254.

6 Burton, L.E., Wilson, W.H. and Shooter, E.M., Nerve growth factor in mouse saliva. Rapid isolation procedures for and characterization of $7 \mathrm{~S}$ nerve growth factor, J. Biol. Chem., 253 (1978) 7807-7812.

7 Carbonetto, S.T., Gruver, M.M. and Turner, D.C., Nerve fiber growth on defined hydrogel substrates, Science, 216 (1982) 897-899.

8 Carbonetto, S., Gruver, M.M. and Turner, D.C., Nerve fiber growth in culture on fibronectin, collagen, and glycosaminoglycan substrates, J. Neurosci., 3 (1983) 2324-2335.

9 Cornbrooks, C.J., Carey, D.J., McDonald, J.A., Timpl, R. and Bunge, R.P., In vivo and in vitro observations on laminin production by Schwann cells, Proc. Natl. Acad. Sci. U.S.A., 80 (1983) 3850-3854

10 Culp, L.A., Electrophoretic analysis of substrate-attached proteins from normal and virus-transformed cells, Biochemistry, 15 (1976) 4094-4104.

11 Daniellson, P.E., Forss-Petter, S., Brow, M.A., Calavetta, L., Douglass, J., Milner, R.J. and Sutcliffe, J.G., p1B15: a cDNA clone of the rat mRNA encoding cyclophilin, DNA, 7 (1988) 261-267.

12 Davis, L.G., Dibner, M.D. and Battey, J.F., Basic Methods in Molecular Biology, Elsevier, Amsterdam, 1986, pp. 130-135.

13 Dziadek, M., Edgar, D., Paulsson, M., Timpl, R. and Fleischmajer, R., Basement membrane proteins produced by Schwann cells and in neurofibromatosis, Ann. N.Y. Acad. Sci., 486 (1986) 248-259

14 Edgar, D., Timpl, R. and Thoenen, H., The heparin-binding domain of laminin is responsible for its effects on neurite outgrowth and neuronal survival, EMBO J., 3 (1984) 1463-1468.

15 Ehrig, K., Leivo, I. and Engvall, E., Merosin and laminin: molecular relationship and role in nerve-muscle development, Ann. N.Y. Acad. Sci., in press.

16 Engvall, E., Davis, G.E., Dickerson, K., Ruoslahti, E., Varon, $S$. and Manthorpe, M., Mapping of domains in human laminin using monoclonal antibodies: localization of the neurite-promoting site, J. Cell. Biol., 103 (1986) 2465-2467.

17 Engvall, E., Leivo, I., Ehrig, K. and Ruoslahti, E., Merosin is a tissue-restricted basement membrane component and a member of a family of laminin-like proteins, J. Cell Biol., 109 (1989) 4 a.

18 Estin, C. and Vernadakis, A., Primary glial cells and brain fibroblasts: interactions in culture, Brain Res. Bull., 16 (1986) $723-731$.

19 Faivre-Bauman, A., Puymiret, J., Loudes, C., Barret, A. and Tixier-Vidal, A., Laminin promotes attachment and neurite elongation of fetal hypothalamic neurons grown in serum-free medium, Neurosci. Lett., 44 (1984) 83-89.

20 Fallon, J.R., Preferential outgrowth of central nervous system neurites on astrocytes and Schwann cells as compared with nonglial cells in vitro, J. Cell Biol., 100 (1985) 198-207.

21 Gilbert, S.F. and Migeon, B.R., D-Valine as a selective agent for normal human and rodent epithelial cells in culture, Cell, 5 (1975) 11-17.

22 Gospodarowicz, D. and Greenburg, G., The role of growth factors and extracellular matrices in the control of mammalian cell proliferation. In M. Ritzen, A. Aperia, K. Hall, A. Larsson, A. Zetterberg T, and Zetterstrom (Eds.), The Biology of Normal Human Growth, Raven Press, New York, 1981, pp. 1-21.

23 Hedgecock, E.M., Culotti, J.G. and Hall, D.H., Unc-5, Unc-6, and $U n c-40$ genes guide circumferential migrations of pioneer axons and mesodermal cells on the epidermis in $C$. elegans, Neuron, in press.

24 Hertz, L., Bock, E. and Schousboe, A., GFA content, glutamate uptake and activity of glutamate metabolizing enzymes in differentiating mouse astrocytes in primary cultures, Dev. Neurosci., 1 (1978) 226-238.

25 Hunter, D.D., Shah, V., Merlie, J.P. and Sanes, J., A laminin-like adhesive protein concentrated in the synaptic cleft of the neuromuscular junction, Nature, 338 (1989) 229-234.

26 Kleinman, H.K., Ebihara, I., Killen, P.D., Sasaki, M., Cannin, F.B., Yamada, Y. and Martin, G.R., Genes for basement membrane proteins are coordinately expressed in differentiating F9 cell but not in normal adult murine tissues, Dev. Biol., 122 (1987) 373-378.

27 Krayanek, S. and Goldberg, S., Oriented extracellular channels and axonal guidance in the embryonic chick retina, Dev. Biol., 84 (1981) 41-50.

28 Kuhl, U., Timpl, R. and yon der Mark, K., Synthesis of type IV collagen and laminin in cultures of skeletal muscle cells and their assembly on the surface of myotubes, Dev. Biol., 93 (1982) 344-354

29 Leivo, I. and Engvall, E., Merosin, a protein specific for basement membranes of Schwann cells, striated muscle, and trophoblast, is expressed late in nerve and muscle development, Proc. Natl. Acad. Sci. U.S.A., 85 (1988) 1544-1548.

30 Leivo, I., Engvall, E., Laurila, P. and Miettinen, M., Distribution of merosin, a laminin-related tissue-specific basement membrane protein, in human Schwann cell neoplasms, Lab. Invest., 61 (1989) 426-432.

31 Letourneau, P.C., Madsen, A.M., Palm, S.L. and Furcht, L.T. Immunoreactivity for laminin in the developing ventral longitudinal pathway of the brain, Dev. Biol., 25 (1988) 135-144.

32 Levi, G., Aloisi, F., Ciotti, M.T. and Gallo, V., Autoradiographic localization and depolarization-induced release of acidic amino acids in differentiating cerebellar granule cell cultures, Brain Res., 190 (1984) 77-86.

33 Liesi, P., Do neurons in the vertebrate CNS migrate on laminin? EMBO J., 4 (1985) 1163-1170.

34 Liesi, P., Dahl, D. and Vaheri, A., Laminin is produced by early rat astrocytes in primary culture, $J$. Cell Biol., 96 (1983) 920-924.

35 Liesi, P. and Risteli, L., Glial cells of mammalian brain produce a variant form of laminin, Exp.Neurol., 105 (1989) 86-92.

36 Liesi, P., Närvänen, Soos, J., Saviola, H. and Shounou, G., Identification of a neurite outgrowth-promoting domain of laminin using synthetic peptides, FEBS Lett., 244 (1989) $141-148$.

37 Manthorpe, M., Engval, E., Ruoslauti, E., Longo, F.M., Davis, G.W. and Varon, S., Laminin promotes neurite regeneration from cultured peripheral and central neurons, J. Cell Biol., 97 (1983) 1882-1890.

38 Mattiessen, H.P., Schmalenbach, C. and Müller, H.W., Astroglia-released neurite growth-inducing activity for embryonic hippocampal neurons is associated with laminin bound in a sulfated complex and free fibronectin, Glia, 2 (1989) 177-188.

39 McLoon, S.C., McLoon, L.K., Palm, S.L. and Furcht, L.T., Transient expression of laminin in the optic nerve of the developing rat, J. Neurosci., 8 (1988) 1981-1990.

40 Noble, M., Fok-Seang, J. and Cohen, J., Glia are a unique substrate for the in vitro growth of central nervous system neurons, J. Neurosci., 4 (1984) 1892-1903.

41 Ogawa, K., Tashiro, K.-I., Laurie, G.W., Sasaki, M. and Yamada, Y., Biological activity of mouse laminin B1 chain expressed in insect cells by a baculovirus vector, J. Cell Biol., submitted.

42 Oorschot, D.E. and Jones, D.G., Tissue culture analysis of neurite outgrowth in the presence and absence of serum possible relevance for central nervous system regeneration, $J$ Neurosci. Res., 15 (1986) 341-352.

43 Price, J. and Hynes, R.O.. Astrocytes in culture synthesize and 
secrete a variant form of fibronectin, J. Neurosci., 5 (1985) 2205-2211.

44 Rogers, S.L., Letourneau, P.C., Palm, S.L., McCarthy, J. and Furcht, L.T., Neurite extension by peripheral and central nervous system neurons in response to substratum-bound fibronectin and laminin, Dev. Biol., 98 (1983) 212-220.

45 Rutka, J.T., Giblin, J., Dougherty, D.V., McCulloch, J.R., DeArmond, S.J. and Rosenblum, M.L., An ultrastructural and immunocytochemical analysis of leptomeningeal and meningioma cultures, J. Neuropathol. Exp. Neurol., 45 (1986) 285-303.

46 Sakellaridis, N., Bau, D., Mangoura, D. and Vernadakis, A., Developmental profiles of glial enzymes in the chick embryo: in vivo and in vitro, Neurochem. Int., 5 (1983) 685-689.

47 Sasaki, M. and Yamada, Y., The laminin B2 chain has a multidomain structure homologous to the B1 chain, J. Biol. Chem., 262 (1987) 17111-17117.

48 Sasaki, M., Kleinman, H.K., Huber, H., Deutzmann, R. and Yamada, Y, Laminin, a multidomain protein, J. Biol. Chem., 263 (1988) 16536-16544

49 Sasaki, M., Kohno, K., Kato, S., Martin, G.R. and Yamada, Y., Sequence of cDNA encoding the laminin B1 chain reveals a multidomain protein containing cysteine-rich repeats, Proc. Natl. Acad. Sci. U.S.A., 84 (1987) 935-939.

50 Selak, I., Foidart, J.M. and Moonen, G., Laminin promotes cerebellar granule cells migration in vitro and is synthesized by cultures astrocytes, Dev. Neurosci, 7 (1985) 278-285.

51 Sephel, G.C., Tashiro, K.-I., Sasaki, M., Kandel, S., Yamada, Y. and Kleinman, H., A laminin-pepsin fragment with cell attachment and neurite outgrowth activity of distinct sites, Dev. Biol., 135 (1989) 172-181.

52 Silver, J., Lorenz, S.E., Wahlsten, D. and Coughlin, J, Axonal guidance during development of the great cerebral commissures: descriptive and experimental studies in vivo on the role of preformed glial pathways, J. Comp. Neurol., 210 (1982) 10-29.

53 Silver, J. and Robb, R.M., Studies on the development of the eye cup and optic nerve in normal mice and in mutants with congenital optic nerve aplasia, Dev. Biol., 68 (1979) 175-190.

54 Silver, J. and Sidman, R.L., A mechanism for the guidance and topographic patterning of retinal ganglion cell axons, J. Comp. Neurol., 189 (1980) 101-111.

55 Singer, M., Nordlander, R.H. and Egar, M., Axonal guidance during embryogenesis and regeneration in the spinal cord of the newt: the blueprint hypothesis of neuronal pathway patterning, J. Comp. Neurol., 185 (1979) 1-22.

56 Skaper, S.D., Selak, I. and Varon, S., Serum- and substratumdependent modulation of neuritic growth, J. Neurosci. Res., 9
(1983) 359-369.

57 Smalheiser, N.R., Crain, S.M. and Reid, L.M., Laminin as a substrate for retinal axons in vitro, Dev. Brain Res., 12 (1984) $136-140$.

58 Tashiro, K., Sephel, G.C., Weeks, B., Sasaki, M., Martin, G.R., Kleinman, H.K. and Yamada, Y., A synthetic peptide containing the IKVAV sequence for the A chain of laminin mediates cell attachment, migration and neurite outgrowth, $J$. Biol. Chem., 264 (1989) 16174-16182.

59 Thangipon, W., Kingsbury, N., Webb, M. and Balazs, R. Observations on rat cerebellar cells in vitro: influence of substratum, potassium concentration and relationship between neurons and astrocytes, Dev. Brain Res., 11 (1983) 177-189.

$60 \mathrm{Timpl}, \mathrm{R}$. and Martin, G.R., Laminin and other basement membrane components, Annu. Rev. Cell Biol., 3 (1987) 57-85.

61 Timpl, R., Rohde, H., Gehron Robey, P., Rennard, S.I., Foidart, J.M. and Martin, G.R., Laminin-A glycoprotein from basement membranes, J. Biol. Chem., 254 (1979) 9933-9937.

62 Tomaselli, K.J., Neugebauer, K.M., Bixby, J.L., Lilien, J. and Reichardt, L.F., N-cadherin and integrins: two receptor systems that mediate neuronal process outgrowth on astrocyte surfaces, Neuron, 1 (1988) 33-43.

63 Tomaselli, K.J., Reichardt, L.F. and Bixby, J.L., Distinct molecular interactions mediate neuronal process outgrowth on non-neuronal cell surfaces and extracellular matrices, $J$. Cell Biol., 103 (1986) 2659-2672.

64 Towbin, H., Staehelin, T. and Gordon, J., Electrophoretic transfer of proteins from polyacrylamide gels to nitrocellulose sheets: procedure and some applications, Proc. Natl. Acad. Sci. U.S.A., 76 (1979) 4350-4354.

65 Tseng, S.C.G., Savion, N., Gospodarowicz, D. and Stern, R., Characterization of collagens synthesized by bovine corneal endothelial cell cultures, J. Biol. Chem., 256 (1981) 3361-3365.

66 Warburton, M.J., Ferns, S.A. and Rudland, P.S., Enhanced synthesis of basement membrane proteins during the differentiation of rat mammary tumour epithelial cells into myoepithelial-like cells, Exp. Cell Res., 137 (1982) 373-380.

67 Wujek, J.R. and Akeson, R.A., Extracellular matrix derived from astrocytes stimulates neuritic outgrowth from PC12 cells in vitro, Dev. Brain Res., 34 (1987) 87-97.

68 Wujek, J.R. and Freese, E., Neurite growth promoting factor(s) of astrocyte extracellular matrix: identity and developmental regulation, Soc. Neurosci. Abstr., 13 (1987) 1484.

69 Wujek, J.R., Lipsky, R.H. and Freese, E., Laminin synthesis in cultured mammalian astrocytes, Soc. Neurosci. Abstr., 14 (1988) 1326 . 